user (range, 247-1839 MCQs) during the 15-week period (105 days). Each MCQ was answered 2.33 times. In total, there were 1167 learning days, with 60.8 days per user (range, 15-95 days). The users spent 30,596 min (509.9 h) answering the MCQs, resulting in 1,610 min (or 26.8 h) per user. Furthermore, each user answered 17.5 MCQs and spent an average of $26 \mathrm{~min}$ per learning day.

Conclusion: Blended learning is an interactive method to potentially extend learning time over several weeks. However, the success of this technique lies in motivating the participants to continue learning after the event. A quiz duel as a gamification technique proved to be effective in motivating participants to learn daily. In our study, learners spent an average of $27 \mathrm{~h}$, i.e., almost half of the total attendance time of $60 \mathrm{~h}$, learning. Correspondingly, this technique could also replace parts of lengthy face-to-face courses in an attempt to save costs in the future. Information drawn from the MCQs could potentially serve as promising learning analytics.

References:

[1] Shivetts, C. E-Learning and Blended Learning: The Importance of the Learner A Research Literature Review. Int. J. E-Learn. 10, 331-337 (2011).

[2] Pesare, E., Roselli, T., Corriero, N. \& Rossano, V. Game-based learning and Gamification to promote engagement and motivation in medical learning contexts. Smart Learn. Environ. 3, 5 (2016).

Disclosure of Interests: Ruben Sengewein: None declared, Patricia Steffens-Korbanka Consultant of: Abbvie, Chugai, Novartis, Sanofi, Mylan, Lilly, Speakers bureau: Abbvie, Chugai, Novartis, Sanofi, Lilly, Joerg Wendler Consultant of: Janssen, AbbVie, Sanofi, Speakers bureau: Roche, Chugai, Janssen, AbbVie, Novartis, Max Kieslich: None declared, Erik Schmok: None declared, Georg Gauler Consultant of: Abbvie, Lilly, MSD, Speakers bureau: Abbvie, Celgene, Novartis, Sanofi,

DOI: 10.1136/annrheumdis-2020-eular.2497

\section{THU0651-HPR ONLINE EDUCATION YIELDS SIGNIFICANT GAINS IN RHEUMATOLOGISTS' KNOWLEDGE OF THE ROLE OF ENTHESITIS IN THE DIAGNOSIS AND MANAGEMENT OF PSA}

A. Stan ${ }^{1}$, M. Calle ${ }^{2}$, P. Schoonheim3, P. J. Mease ${ }^{4} .{ }^{1}$ Medscape, LLC, New York, United States of America; ${ }^{2}$ Medscape, LLC, New York, United States of America; ${ }^{2}$ Medscape, LLC, New York, United States of America; ${ }^{4}$ University of Washington School of Medicine Seattle, Rheumatology Research Swedish Medical Center, Seattle, United States of America

Background: Physicians face challenges staying up-to-date with the latest research and accessing the ever-growing field of knowledge is time-consuming. Online education can make these clinician's tasks more efficient and less time-consuming.

Objectives: As part of a larger curriculum, we developed an online CME activity titled: "Enthesitis in Psoriatic Arthritis: Disease, Diagnosis and Decisions". The goal of this study was to assess whether this online CME accredited video discussion improves physicians' understanding of the role of enthesitis in the diagnosis and management of patients with psoriatic arthritis (PsA) in clinical practice.

Methods: Rheumatologists participated in an online CME activity (https://www. medscape.org/viewarticle/910671) consisting of a 30-minute video discussion between 2 experts with accompanying slides. Educational effect was assessed using a 4-question repeated pairs, pre-/post-assessment. A chi-square test was used to determine if a statistically significant improvement $(P<.05$ significance level) existed in the number of correct responses from the pretest and posttest scores. Cramer's $V$ was used to estimate the level of impact of the education. The CME activity launched on March 28, 2019, and the data were collected through June 7, 2019

Results: A total of 145 rheumatologists completed the pre- and post activity assessments. Overall the activity had a signficiant impact $(P<.0001)$ on rheumatologists' knowledge of the role of enthesitis in the diagnosis and management of PsA, with a Cramer's V value of 0.153 indicating a noticeble educational impact. The average percentage of correct responses rose from $54 \%$ pre-activity to $69 \%$ post-activity. A repeated pairs analysis showed that $22 \%$ of rheumatologists improved their knowledge and $47 \%$ reinforced their knowledge, respectively. The change in percentage of correct responses from pre- to post-assessment for all questions are shown in table. Almost
Table. Impact of education on rheumatologists' knowledge of enthesitis

\begin{tabular}{|c|c|c|c|c|c|}
\hline \multirow[t]{2}{*}{ Question \# } & \multirow[t]{2}{*}{ Question topic } & \multicolumn{2}{|c|}{ Aggregated data } & \multicolumn{2}{|c|}{ Linked Learner Results ${ }^{a}$} \\
\hline & & $\begin{array}{c}\text { Average } \% \text { of } \\
\text { correct responses } \\
\text { Pre- vs. } \\
\text { Post-education }\end{array}$ & P-value & $\begin{array}{l}\text { \% } \text { Improved }^{\mathrm{b}} \\
\text { learners } \\
\text { Pre- vs. Post- } \\
\text { education }\end{array}$ & $\begin{array}{l}\% \text { Reinforced }^{\mathrm{c}} \\
\text { learners } \\
\text { Pre- vs. } \\
\text { Post-education }\end{array}$ \\
\hline 1. & $\begin{array}{c}\text { Immunopathology } \\
\text { of PsA }\end{array}$ & $75 \%$ vs $84 \%$ & .0579 & $12 \%$ & $72 \%$ \\
\hline 2. & $\begin{array}{c}\text { Prevalence of } \\
\text { enthesitis in patients } \\
\text { with PsA }\end{array}$ & $44 \%$ vs $68 \%$ & $<.0001$ & $33 \%$ & $34 \%$ \\
\hline 3. & $\begin{array}{l}\text { Clinical trial out- } \\
\text { comes in patients } \\
\text { with enthesitis }\end{array}$ & $43 \%$ vs $56 \%$ & .0345 & $22 \%$ & $34 \%$ \\
\hline
\end{tabular}

${ }^{\mathrm{a} E a c h}$ individual learner tracked pre and post-education

${ }^{\mathrm{b}}$ Incorrect answer pre-education, Correct answer post-education

${ }^{c}$ Correct answer pre-education, Correct answer post-education

$40 \%$ of rheumatologists had a measurable improvement in confidence in their ability to evaluate the presence of enthesitis according to a clinical exam or ultrasound.

Conclusion: This online CME activity significantly improved rheumatologists understanding of role of enthesitis in the diagnosis and management of PsA However, there is clearly room for further improving physicians' knowledge of clinical trial outcomes with biologics in patients with enthesitis, since $44 \%$ of rheumatologists provided incorrect answers to question 3 post-education. This topic can be addressed in future education.

Acknowledgments: This CME-certified activity was supported by independent funding from Novartis AG.

Disclosure of Interests: Adriana Stan Grant/research support from: The CME-certified activity was supported by an independent educational gran from Sandoz., Marinella Calle Grant/research support from: This CME-certified activity was supported by an independent educational grant from Novartis AG Peter Schoonheim Grant/research support from: This CME-certified activity was supported by independent funding from Sandoz., Philip J Mease Grant/ research support from: Abbott, Amgen, Biogen Idec, BMS, Celgene Corporation, Eli Lilly, Novartis, Pfizer, Sun Pharmaceutical, UCB - grant/research support, Consultant of: Abbott, Amgen, Biogen Idec, BMS, Celgene Corporation, Eli Lilly, Novartis, Pfizer, Sun Pharmaceutical, UCB - consultant, Speakers bureau: Abbott, Amgen, Biogen Idec, BMS, Eli Lilly, Genentech, Janssen, Pfizer, UCB - speakers bureau

DOI: 10.1136/annrheumdis-2020-eular.3137

\section{THU0652-HPR ONLINE EDUCATION YIELDS SIGNIFICANT GAINS IN RHEUMATOLOGISTS' KNOWLEDGE OF BIOLOGICS AND BIOSIMILARS BUT A SUBSTANTIAL GAP} REMAINS

A. $\operatorname{Stan}^{1}$, E. Bell ${ }^{2}$, P. Schoonheim ${ }^{2}$, E. Mysler ${ }^{3} .{ }^{1}$ Medscape, LLC, New York, United States of America; ${ }^{2}$ Medscape, LLC, New York, United States of America; ${ }^{3}$ Organización Médica de Investigación (OMI), Buenos Aires, Argentina

Background: Biologics are complex proteins which have revolutionized the treatment of many serious diseases. Due to their complexity and manufacturing which involves living organisms, it is not possible to create identical versions of reference biologics, but it is possible to create biosimilar drugs. Biosimilars have the potential to yield high cost savings and expand treatment options to meet the growing demand for biological therapies.

Objectives: This study assessed whether the online CME-accredited round-table-discussion titled "Understanding Biologics: from protein to clinical practice" improved physicians' understanding of the inherent variability of biologics and what similarity means in the context of biologics as well as the analytical assessment of quality that applies to both biologics and biosimilars. 
Methods: Rheumatologists participated in an online CME activity (www medscape.org/viewarticle/900121) consisting of a 30-minute video discussion between 4 experts with accompanying slides. Educational effect was assessed using a 4-question repeated pairs, pre-/post-assessment. A chisquare test was used to determine if a statistically significant improvement ( $P<.05$ significance level) existed in the number of pre-/post-test correct responses. Cramer's V was used to estimate the level of impact of the education. The CME activity launched on 22 Aug 2018, and the data were collected through 9 Oct 2018.

Results: A total of 622 rheumatologists participated in the educational activity, and 87 completed the pre- and postassessment. Overall the activity had a signficiant impact $(P<.001)$ on rheumatologists' understanding of the inherent variability of biologics and the regulatory requirements for approval of a biosimilar. The Cramer's $V$ value of 0.186 indicates a considerable effect of the education. The average perecentage of correct responses rose from $33 \%$ pre-activity to $51 \%$ post-activity. A linked learning assessment (individual responses matched pre- and post-education) showed that $25 \%$ of learners improved their knowledge and $26 \%$ reinforced their knowledge. The change in percentage of correct responses from pre- to post-assessment achieved statistical significance $(P<.05)$ in 2 of the 3 questions presented: (i) understanding the type of studies needed to demonstrate comparability of a biosimilar to an originator ( $11 \%$ at baseline; $45 \%$ post activity), (ii) understanding the type of variability considered acceptable for a biologic (46\% at baseline; $63 \%$ post activity). However, no knowledge gain was observed regarding basic analytic attributes evaluated to ensure batch to batch consistency $(37 \%$ at baseline; $38 \%$ post activity). Almost $45 \%$ of rheumatologists gained confidence in their ability to describe the regulatory requirements for approval of a biosimilar.

Conclusion: This online CME activity significantly improved rheumatologists' understanding of the inherent variability of complex biologic medicines and the role of analytical studies in the regulatory approval of biosimilars. However, there is room for further improving physicians' knowledge, especially of basic analytics of biologics and biosimilars.

Acknowledgments: This CME-certified activity was supported by independent funding from Sandoz.

Disclosure of Interests: Adriana Stan Grant/research support from: The CME-certified activity was supported by an

independent educational grant from Sandoz., Elaine Bell: None declared, Peter Schoonheim Grant/research support from: This CME-certified activity was supported by independent funding from Sandoz., Eduardo Mysler Grant/ research support from: AbbVie, Lilly, Pfizer, Roche, BMS, Sandoz, Amgen, and Janssen., Consultant of: AbbVie, Lilly, Pfizer, Roche, BMS, Sandoz, Amgen, and Janssen.

DOI: 10.1136/annrheumdis-2020-eular.6048

\section{THU0653-HPR BARRIERS FOR THE UPTAKE OF EULAR POSTGRADUATE EDUCATION FOR HEALTH PROFESSIONALS IN RHEUMATOLOGY IN EASTERN EUROPEAN COUNTRIES: RESULTS FROM 3 NATIONAL SURVEYS}

L. Van Bodegom-Vos ${ }^{1}$, T. P. M. Vliet Vlieland ${ }^{2}$, L. Carmona ${ }^{3}$, N. Damjanov ${ }^{4}$,

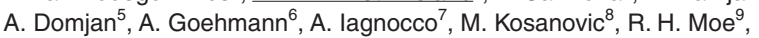
W. Peter ${ }^{2}$, M. Segrt ${ }^{10}$, E. Tonga ${ }^{11}$, C. Zabalan ${ }^{12}$. ${ }^{1}$ Leiden University Medical Center, Biomedical Data Sciences, Leiden, Netherlands; ${ }^{2}$ Leiden University Medical Center, Leiden, Netherlands; ${ }^{3}$ InMusc, Madrid, Spain; ${ }^{4}$ Belgrade University School of Medicine, Institute of Rheumatology, Belgrade, Serbia; ${ }^{5}$ University of Debrecen, Debrecen, Hungary; ${ }^{6}$ EULAR, PARE, Zurich, Switzerland; ${ }^{7}$ University of Turin, Turin, Italy; ${ }^{8} \mathrm{ORS}$, Belgrade, Serbia; ${ }^{9}$ Diakonhjemmet Hospital, Dept of Rheumatology, Oslo, Norway; ${ }^{10}$ Serbian Association of Health Professionals in Rheumatology, Belgrade, Serbia; ${ }^{11}$ Marmara University, Istanbul, Turkey; ${ }^{12}$ Romanian League Against Rheumatism, Bucharest, Romania

Background: Health professionals play an important role in the care for people with rheumatic and musculoskeletal diseases. In order to improve and maintain the quality of their work, appropriate professional education is needed. EULAR has developed several educational products and activities specifically targeted at Health Professionals in Rheumatology (HPR), but particularly in Eastern European countries, their uptake is limited. The overarching aim of a EULAR project (named HEE4ALL: Health professionals Education in Eastern European countries for All) is to develop and execute implementation strategies for EULAR educational activities in 3 eastern European countries.

Objectives: The aim of the present analysis was to identify barriers and facilitators for the uptake of EULAR educational activities among HPR in Eastern European countries.

Methods: First, a questionnaire was sent to representatives of national health professionals' or patients' organization in 17 Eastern European countries, in order to determine their eligibility to participate in the implementation project. Eligibility criteria were: Having a national HPR organization; Willing and able to compose a team with HPR, Patients, and Rheumatologists; and Interested to participate in the project. Selected countries (minimum 3 ) were requested to set up a national implementation team, and conduct a national, electronic survey among HPR on anticipated barriers and needs regarding educational activities. The survey included the following elements: a. characteristics of the responding HPRs; $b$. Familiarity with EULAR educational offerings; c. Anticipated barriers and facilitators (score $0=$ no barrier at all to 10 very important barrier); $d$. Ability to pay for the HPR online course.

Results: Representatives from 10/17 Eastern European countries responded to the first questionnaire, with 3 countries meeting the selection criteria: Hungary, Serbia and Turkey. Subsequently, 216 (H:106, S:42 and T:68) HPR completed the 3 national surveys. In all 3 countries, the majority of the respondents was female $(93.1 \%)$, and nurse $(70.8 \%)$ or physical therapist (19.0). Familiarity with EULAR educational offerings was poor, with the lowest proportions of HPR being familiar with postgraduate face-to-face courses (13.9\%), educational visits $(19.0 \%)$ and the EULAR online course for HPR $(25.0 \%)$. The highest ranked barriers in all 3 countries included the costs of EULAR annual congress, the costs of the EULAR HPR online course and a lack of mastery of English language.The maximum amount of money HPR were able to pay for the EULAR online course was on average €66, €29 and €83 in Hungary, Serbia and Turkey, respectively.

Conclusion: Based on a survey in 3 Eastern European countries, it appears that familiarity with EULAR educational offerings is suboptimal. However, when HPR are aware of the educational offerings, their costs and a lack of mastery of the English language seem to be the most important barriers for participation. Based on these results, the 3 national teams developed implementation plans during a 2-day meeting (October 2019). The implementation plans are now executed and a process and effect evaluation is planned by November, 2020

\section{Acknowledgments: Supported by EULAR; Project HPR 042}

Disclosure of Interests: Leti van Bodegom-Vos: None declared, T.P.M. Vliet Vlieland: None declared, Loreto Carmona Grant/research support from: Novartis Farmaceutica, SA, Pfizer, S.L.U., Merck Sharp \& Dohme España, S.A., Roche Farma, S.A, Sanofi Aventis, AbbVie Spain, S.L.U., and Laboratorios Gebro Pharma, SA (All trhough institution), Nemanja Damjanov Grant/ research support from: from AbbVie, Pfizer, and Roche, Consultant of: AbbVie, Gedeon Richter, Merck, Novartis, Pfizer, and Roche, Speakers bureau: AbbVie, Gedeon Richter, Merck, Novartis, Pfizer, and Roche, Andrea Dom jan: None declared, Alzbeta Goehmann: None declared, Annamaria lagnocco Grant/research support from: Abbvie, MSD and Alfasigma, Consultant of: AbbVie, Abiogen, Alfasigma, Biogen, BMS, Celgene, Eli-Lilly, Janssen, MSD Novartis, Sanofi and Sanofi Genzyme, Speakers bureau: AbbVie, Alfasigma, BMS, Eli-Lilly, Janssen, MSD, Novartis, Sanofi, Marija Kosanovic: None declared, Rikke Helene Moe: None declared, Wilfred Peter: None declared, Marija Segrt: None declared, Eda Tonga: None declared, Codruta Zabalan: None declared DOI: 10.1136/annrheumdis-2020-eular.4480 